\title{
Interleukin-17A (IL-17A): the silent amplifier of COVID-19
}

\author{
Francesco Maione ${ }^{1}$, Gian Casillo ${ }^{2}$, Federica Raucci ${ }^{1}$, and Mariarosaria Bucci ${ }^{1}$ \\ ${ }^{1}$ University of Naples Federico II Department of Pharmacy \\ ${ }^{2}$ University of Naples Federico II School of Medicine and Surgery
}

April 12, 2021

\begin{abstract}
One of the hallmarks of COVID-19 is the cytokine storm that provokes primarily pneumonia followed by systemic inflammation. Emerging evidence has identified a potential link between elevated levels of interleukin-17A (IL-17A) and disease severity and progression. Considering that per se IL-17A can activate several inflammatory pathways, it is plausible to hypothesize an involvement of this cytokine in COVID-19 clinical outcomes. Thus, this cytokine can represent a marker of disease progression and/or a target to develop therapeutic strategies. This hypothesis paper aims to propose this "unique" cytokine as a silent amplifier of the COVID-19 immune response and (potentially) related therapy.
\end{abstract}

\section{Hosted file}

Maione $\mathrm{F}$ et al, Manuscript.pdf available at https://authorea.com/users/363869/articles/ 517760-interleukin-17a-il-17a-the-silent-amplifier-of-covid-19

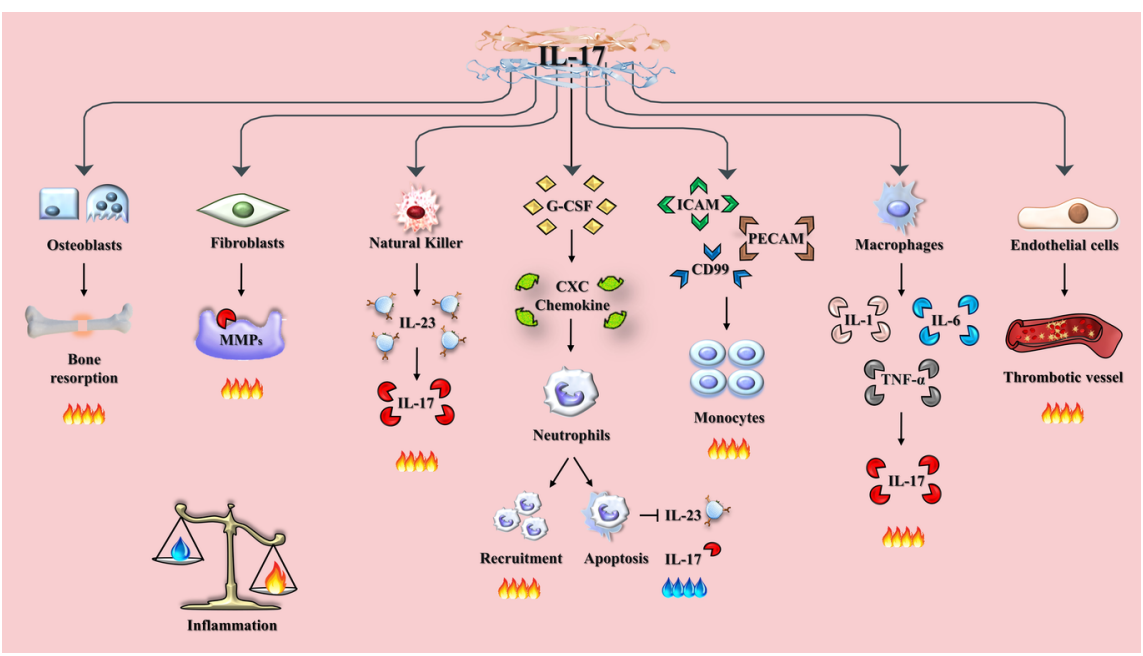




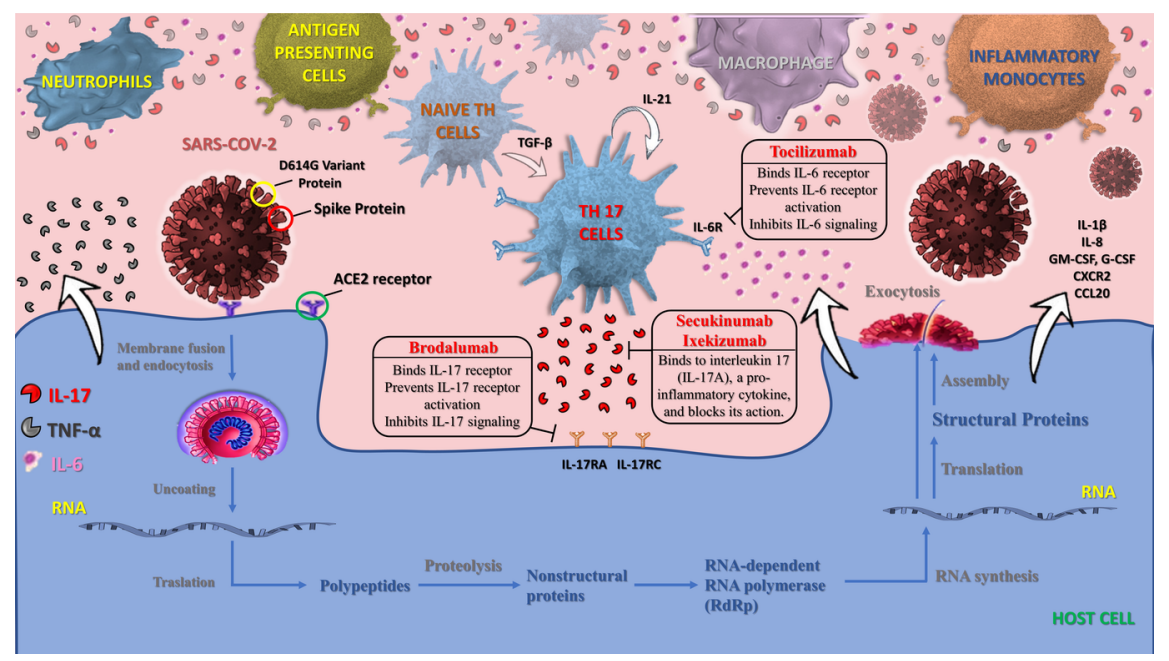

